\title{
Changes in Left Ventricular Function in Alcoholic Beverage Drinkers
}

\author{
Prawpan Suwanakitch ${ }^{1 *}$, Chutiwan Jaichuen', Kanjana Jittiporn' and Tomon Thongsri ${ }^{2}$ \\ 'Department of Cardio-Thoracic Technology, Faculty of Allied Health Sciences, Naresuan University, \\ Phitsanulok - 65000, Thailand; \\ prawpuns@hotmail.com,waen.mixberry@hotmail.com, kanjanaj@nu.ac.th \\ 2Department of Medicine, Buddhachinaraj Phitsanulok Hospital, Phitsanulok - 65000, Thailand; \\ ttomon@hotmail.com
}

\begin{abstract}
Background: Chronic excessive alcohol consumption could lead to the progressive cardiac dysfunction known as Alcoholic cardiomyopathy (ACM). An evaluation form for the assessment of alcohol problems (Alcohol Use Disorders Identification Test: AUDIT) is a simple tool to screen alcohol problems for primary care. However, the link between the use of AUDIT and the diagnosis of heart disease in Thailand is limited. Objective: This study aimed to evaluate the left ventricular function of alcoholic beverage drinkers by echocardiography according to the severity of alcoholic consumption. Methods: Sixty regular alcoholic beverage drinkers, aged over 20 and living in Tambol Thapho, Muang, Phitsanulok Province, was enrolled in this study from January to May 2016. Data was collected from interviews regarding general information. The AUDIT evaluation form was used to assess alcohol problems, physical examinations, and echocardiography were performed. Echocardiographic measurement data were compared between the alcohol beverage drinkers group and a control group. Finding: The Left Ventricular Internal Diameter (LVID) of alcoholic beverage drinkers with AUDIT score levels of 2, 3 and 4 were significantly higher than the control group (at $\mathrm{p}<0.05, \mathrm{p}<0.05, \mathrm{p}<0.05$, respectively).The Left Ventricular Ejection Fraction (LVEF) (Teicholz), of alcoholic beverage drinkers with an AUDIT score of level 4 was significantly lower than the control group $(\mathrm{p}<0.05)$. Moreover, the percentage of alcoholic beverage drinkers with abnormal left ventricular diastolic dysfunction with AUDIT score levels of 1, 2, 3 and 4 were $33.33 \%, 46.67 \%, 46.67 \%$ and $46.67 \%$, respectively. Application: The present study demonstrated alcoholic beverage drinkers had systolic and diastolic dysfunctions. Therefore, the AUDIT evaluation form may be beneficial to screen for the risk of heart failure in alcoholic beverage drinkers in primary health care.
\end{abstract}

Keywords: Alcohol Use Disorders Identification Test, Alcohol consumption, Alcoholic cardiomyopathy, Diastolic dysfunction, Systolic dysfunction

\section{Introduction}

Alcohol consumption caused about 2.7 million deaths and 3.9\% of Disability-Adjusted Life Years (DALYs) in 2010. The harmful use of alcohol causes more than 200 diseases and injury conditions and is a social and economic burden in societies ${ }^{1}$. There are many diseases resulting from alcohol consumption occurring in the gastro-intestinal system (liver cirrhosis, gastro-intestinal bleeding, and pancreatitis), the central nervous system, the respiratory system and the cardiovascular system². Moreover, it has been reported that chronic excessive alcohol consumption has caused dilated alcoholic cardiomyopathy $(\mathrm{ACM})^{3}$. The diagnosis of ACM is based upon a history of heavy and prolonged alcohol use and signs and symptoms of heart failure. Left ventricular (LV) dilatation, increased LV mass, LV wall thinning and systolic and diastolic LV dysfunction characterize $\mathrm{ACM}^{4-6}$. Diastolic LV dysfunc-

${ }^{*}$ Author for correspondence 
tion usually precedes systolic dysfunction and occurs more frequently once systolic impairment becomes apparent by echocardiography ${ }^{\mathrm{T}}$. It has been reported that echocardiography is a non-invasive technique for the diagnosis and serial follow-up of patients with impaired cardiac function. The sensitivity and specificity of echocardiography used in this diagnosis were $80 \%$ and $88 \%$. It has been noted that the prevalence of risky drinking in general, was higher for patient attending primary care services than in the general population?. AUDIT, as recommended by the WHO, is the most widely used alcohol misuse screening tool in primary care clinical settings. The advantages of AUDIT are that it is an international standard, has good sensitivity and specificity, is effective in diagnosing drinking behavior, has short questions and requires a short response time. The AUDIT questionnaire consists of 10 items administered during a face-to-face interview and results can be classified into 4 groups: level 1 (low- risk drinking), level 2 (hazardous drinking), level 3 (harmful use), and level 4 (alcohol dependence). In this study, the AUDIT questionnaire Thai version was used ${ }^{10}$. It has been reported that alcohol is the third most significant health risk for Thai men ${ }^{11}$. A survey in Bangkok, Thailand, showed that the majority of alcohol drinkers in a random sample were male $(67.6 \%)$, mean aged $37.67 \pm 14.81$ years. The results for alcohol misuse among these drinkers, as assessed by AUDIT, were that $61.9 \%$ were low-risk drinkers and $38.1 \%$ were hazardous and harmful drinkers ${ }^{12}$. Moreover, abnormal electrocardiograms were detected in drinkers at all risk levels of the AUDIT evaluation form $\frac{13}{}$. The link between the results of an AUDIT evaluation and the diagnosis of heart disease by echocardiography in Thailand is not available due to a lack of data. This study aimed to evaluate the LV function of alcoholic beverage drinkers by echocardiography according to the AUDIT evaluation form.

\section{Methods}

\subsection{Study Population}

Sixty regular alcoholic beverage drinkers, aged over 20 and living in Tambol Thapho, Muang, Phitsanulok Province, from January to May 2016, were enrolled in the study. Subjects with any one of the following were excluded: a documented history of cardiovascular disease, hypertension, diabetes mellitus, thyroid disease, body mass index
$>30 \mathrm{~kg} / \mathrm{m}^{2}$, primary mitral regurgitation or poor echocardiography imaging. For comparison, 10 healthy subjects without an alcoholic drinking history were studied as the control group. The Naresuan University Institutional Review Board approved the study and all subjects gave written informed consent.

\subsection{Study Protocol}

Data on baseline demographics and clinical characteristics were obtained. Alcoholic drinking histories were obtained from interviews using the Alcohol Use Disorders Identification Test (AUDIT) and classified into 4 groups: level 1 (low-risk drinking), level 2 (hazardous drinking), level 3 (harmful use) and level 4 (alcohol dependence). Measurements of body mass index, Waist Circumference (WC), heart rate, and Blood Pressure (BP) were also collected.

\subsection{Echocardiography}

All alcoholic beverage drinkers and the control group were imaged in the left lateral decubitus position using an echocardiography system (GE-VingMed, Horten, Norway) with a $3 \mathrm{~S}$ transducer. The images were digitally stored on $\mathrm{CD}$ for later analysis. The echocardiography was performed by a Cardiothoracic Technologist. The intraobserver and inter-observer reliability were evaluated. Echocardiography in M-mode was performed for wall thickness, the internal diameter of LV measurement and Ejection Fraction (EF). The 2D Simpson EF was measured as an estimation of LV systolic function. Pulsed-wave Doppler ultrasound scans for mitral valve inflow were evaluated for LV diastolic function, peak early diastolic velocity (E), peak late diastolic velocity (A) and E/A ratio. Using tissue Doppler imaging, the early diastolic velocity (E') was measured at the level of the LV basal lateral segment. In addition, the E/E' ratio was calculated as an estimation of LV filling pressure. LV diastolic dysfunction was categorized as: normal; defined by normal LV function, mild: defined by LV impaired relaxation without evidence of increased filling pressure, moderate; defined by LV impaired relaxation associated with moderate elevation of filling pressure or pseudonormal filling, and severe; defined by restrictive LV filling.

\subsection{Statistical Analysis}

Data were expressed as mean \pm S.D. for continuous variables and frequencies. The Chi-square test was used for 
Table 1. Clinical characteristics of alcoholic beverage drinkers and controls

\begin{tabular}{|l|c|c|c|c|c|}
\hline \multirow{2}{*}{ Variables } & \multirow{2}{*}{ Controls (n=10) } & \multicolumn{4}{|c|}{ AUDIT score of alcoholic beverage drinkers } \\
\cline { 3 - 6 } & & Level 1 (n=15) & Level 2 (n=15) & Level 3 (n=15) & Level 4 (n=15) \\
\hline Age (years) & $50.00 \pm 9.26$ & $41.80 \pm 12.99$ & $40.73 \pm 14.58$ & $45.93 \pm 11.74$ & $46.73 \pm 8.98$ \\
\hline Male, n (\%) & $8(80.0)$ & $11(73.3)$ & $13(86.7)$ & $13(86.7)$ & $14(93.3)$ \\
\hline BMI $\left(\mathrm{kg} / \mathrm{m}^{2}\right)$ & $24.17 \pm 2.24$ & $23.57 \pm 2.65$ & $25.29 \pm 3.86$ & $23.23 \pm 3.81$ & $21.39 \pm 3.25^{+}$ \\
\hline WC $(\mathrm{cm})$ & $84.80 \pm 6.86$ & $86.07 \pm 9.14$ & $89.53 \pm 9.75$ & $86.47 \pm 9.55$ & $82.33 \pm 9.03$ \\
\hline HR (bpm) & $75.00 \pm 9.70$ & $78.33 \pm 13.00$ & $77.00 \pm 11.48$ & $76.27 \pm 11.30$ & $84.80 \pm 11.82$ \\
\hline SBP (mmHg) & $123.50 \pm 6.86$ & $124.27 \pm 13.52$ & $123.33 \pm 15.12$ & $127.60 \pm 16.30$ & $134.77 \pm 18.92$ \\
\hline DBP (mmHg) & $74.10 \pm 7.50$ & $75.67 \pm 9.00$ & $79.00 \pm 10.49$ & $80.80 \pm 11.62$ & $84.13 \pm 9.10$ \\
\hline Smoker, n (\%) & $0(0.0)$ & $6(40.0)^{*}$ & $7(46.7)^{*}$ & $9(60.0)^{*}$ & $11\left(73.30^{*}\right.$ \\
\hline
\end{tabular}

Data presented are mean value \pm SD or number (\%) of subjects, $\mathrm{BMI}=$ body mass index, $\mathrm{WC}=$ waist circumference, $\mathrm{HR}$ $=$ heart rate, $\mathrm{SBP}=$ systolic blood pressure, $\mathrm{DBP}=$ diastolic blood pressure. ${ }^{*} \mathrm{p} \leq 0.05$ vs. controls; ${ }^{+} \mathrm{p} \leq 0.05$ vs. AUDIT score level 2

comparison of nonparametric data and the t-test was used to compare continuous variables. Analysis of variance was used to compare differences for the four group's AUDIT scores and the control group, with individual group comparisons analyzed by the Tukey's HSD test. A p-value $<0.05$ was considered statistically significant.

\section{Results}

\subsection{Clinical Characteristics}

The baseline characteristics of alcoholic beverage drinkers and controls are shown in Table 1 . The age, waist circumference, heart rate and systolic blood pressure were similar in each level of AUDIT score and the controls. Nevertheless, AUDIT score levels of 1-4 had more smokers than controls. The body mass index of AUDIT score level 4 was significantly lower than level $2(\mathrm{p}<0.05)$. In contrast, the diastolic blood pressure of AUDIT score level 4 seemed higher than the controls but the statistical value was not different.

\subsection{Echocardiography Measurements}

The LVID of alcoholic beverage drinkers with AUDIT score levels of 2-4 was significantly higher than the control group $(\mathrm{p}<0.05, \mathrm{p}<0.05, \mathrm{p}<0.05$, respectively) but there was no difference in the inter-ventricular septum and left ventricular posterior wall thickness. The LVEF of alcoholic beverage drinkers with an AUDIT score level of 4 was significantly lower than the control group $(\mathrm{p}<0.05)$. The LVEF Simpson of alcoholic beverage drinkers with an AUDIT score level of 1-4 tended to decrease from 1 to 4 but there was no statistical difference. A comparison of Doppler echocardiography parameters in each AUDIT score of alcoholic beverage drinkers and the controls are shown in Table 2. There was no difference between AUDIT score levels in early diastolic filling velocity (E velocity), late diastolic filling velocity (A velocity), Deceleration Time (DT), Isovolumic Relaxation Time (IVRT), ratio of peak early diastolic velocity to late diastolic velocity of mitral inflow (E/A ratio), early diastolic velocity at LV basal septal segment (E'septal), early diastolic velocity at $\mathrm{LV}$ basal lateral segment (E' lateral), ratio of peak early diastolic velocity to early diastolic velocity at LV basal septal segment (Septal E/E') and ratio of peak early diastolic velocity to early diastolic velocity at LV basal lateral segment (Lateral E/E'). The left ventricular diastolic dysfunction grade of alcoholic beverage drinkers and controls are shown in Table 3. Abnormal left ventricular diastolic dysfunction was detected in $33.33 \%$ in alcoholic beverage drinkers with an AUDIT score level of 1 . The percentage of abnormal left ventricular diastolic dysfunction in alcoholic beverage drinkers with 
Table 2. Echocardiographic measurement of alcoholic beverage drinkers and controls

\begin{tabular}{|c|c|c|c|c|c|}
\hline \multirow{2}{*}{ Variables } & \multirow{2}{*}{ Controls $(n=10)$} & \multicolumn{4}{|c|}{ AUDIT score of alcoholic beverage drinkers } \\
\hline & & Level $1(n=15)$ & Level $2(n=15)$ & Level $3(n=15)$ & Level $4(n=15)$ \\
\hline IVS (mm) & $10.13 \pm 1.03$ & $10.31 \pm 1.63$ & $10.67 \pm 1.11$ & $10.25 \pm 0.5$ & $10.28 \pm 1.72$ \\
\hline $\operatorname{LVID}(\mathrm{mm})$ & $42.42 \pm 5.78$ & $46.55 \pm 3.57$ & $47.93 \pm 5.77^{\star}$ & $49.37 \pm 5.34^{*}$ & $49.16 \pm 3.65^{*}$ \\
\hline LVPWT $(\mathrm{mm})$ & $10.02 \pm 1.05$ & $9.92 \pm 1.19$ & $10.44 \pm 0.91$ & $10.17 \pm 1.09$ & $10.51 \pm 1.25$ \\
\hline LVEF Teicholz (\%) & $70.80 \pm 3.48$ & $68.49 \pm 4.28$ & $68.65 \pm 6.91$ & $66.50 \pm 7.21$ & $62.10 \pm 8.28^{*}$ \\
\hline LVEF Simpson (\%) & $69.05 \pm 7.01$ & $67.23 \pm 4.71$ & $65.72 \pm 5.73$ & $64.44 \pm 4.55$ & $61.86 \pm 8.61$ \\
\hline E velocity $(\mathrm{m} / \mathrm{s})$ & $0.74 \pm 0.15$ & $0.67 \pm 0.16$ & $0.71 \pm 0.10$ & $0.77 \pm 0.15$ & $0.67 \pm 0.13$ \\
\hline A velocity $(\mathrm{m} / \mathrm{s})$ & $0.60 \pm 0.12$ & $0.59 \pm 0.14$ & $0.58 \pm 0.15$ & $0.60 \pm 0.17$ & $0.64 \pm 0.17$ \\
\hline $\mathrm{DT}(\mathrm{ms})$ & $196.96 \pm 19.80$ & $211.21 \pm 53.07$ & $193.80 \pm 42.07$ & $187.83 \pm 38.43$ & $193.81 \pm 46.65$ \\
\hline IVRT (ms) & $73.25 \pm 13.66$ & $77.16 \pm 10.94$ & $75.07 \pm 8.25$ & $73.80 \pm 7.42$ & $75.63 \pm 8.22$ \\
\hline $\mathrm{E} / \mathrm{A}$ ratio & $1.14 \pm 0.40$ & $1.19 \pm 0.39$ & $1.29 \pm 0.39$ & $1.40 \pm 0.44$ & $1.06 \pm 0.32$ \\
\hline E' septal $(\mathrm{m} / \mathrm{s})$ & $0.09 \pm 0.02$ & $0.09 \pm 0.02$ & $0.09 \pm 0.03$ & $0.09 \pm 0.03$ & $0.08 \pm 0.02$ \\
\hline E' lateral $(\mathrm{m} / \mathrm{s})$ & $0.11+0.02$ & $0.11 \pm 0.03$ & $0.10 \pm 0.02$ & $0.11 \pm 0.03$ & $0.11 \pm 0.03$ \\
\hline Septal E/E' & $7.77 \pm 2.85$ & $7.49 \pm 2.52$ & $7.00 \pm 2.82$ & $7.15 \pm 2.51$ & $7.16 \pm 2.15$ \\
\hline Lateral E/E' & $7.04 \pm 2.91$ & $6.30 \pm 1.98$ & $6.91 \pm 1.75$ & $7.30 \pm 2.12$ & $6.53 \pm 2.25$ \\
\hline
\end{tabular}

Data presented are mean value $\pm S D, n=$ number of subjects, IVS = interventricular septum, LVID = left ventricular internal diameter, LVPWT = left ventricular posterior wall thickness, LVEF = left ventricular ejection fraction, E velocity = early diastolic filling velocity, A velocity = late diastolic filling velocity, DT $=$ deceleration time, IVRT $=$ isovolumic relaxation time, E/A ratio = ratio of peak early diastolic velocity to late diastolic velocity of mitral inflow, E' septal = early diastolic velocity at LV basal septal segment, E' lateral = early diastolic velocity at LV basal lateral segment, Septal E/E' = ratio of peak early diastolic velocity to early diastolic velocity at LV basal septal segment, Lateral E/E' = ratio of peak early diastolic velocity to early diastolic velocity at LV basal lateral segment. ${ }^{\star} \mathrm{p} \leq 0.05$ vs. controls.

AUDIT score levels of 2, 3 and 4 were $46.67 \%, 46.67 \%$, and $46.67 \%$, respectively as shown in Table 3 and Figure 1. Pseudonormal diastolic dysfunction was found in alcoholic beverage drinkers with AUDIT score levels of 2, 3 and 4 as shown in Table 3 and Figure 2.

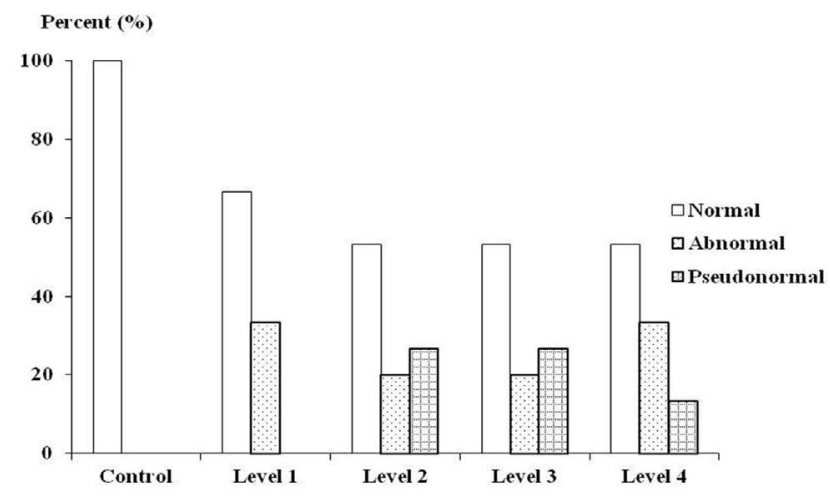

Figure 1. Percentage (\%) of normal, abnormal and pseudonormal diastolic dysfunction of Alcoholic beverage drinkers and controls.

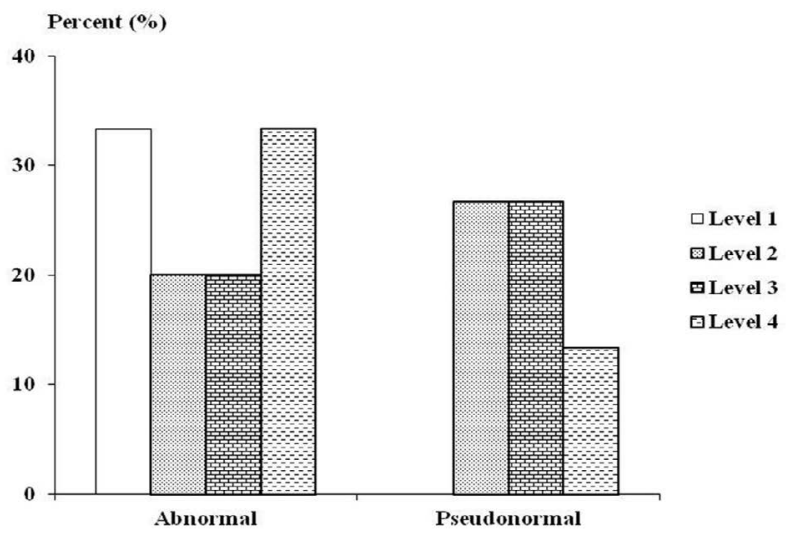

Figure 2 Percentage (\%) of abnormal and pseudonormal diastolic dysfunction in each level of AUDIT score of alcoholic beverage drinkers.

\section{Discussion and Limitation}

The present study showed that healthy alcoholic beverage drinkers with AUDIT score levels of 1-4 had decreased 
left ventricular ejection fractions and abnormal Doppler transmittal flow patterns indicating impaired LV relaxation. Abnormal diastolic function and pseudonormal diastolic function were found in drinkers with AUDIT score levels of 1-4.

Table 3. Left ventricular diastolic dysfunction of alcoholic beverage drinkers and controls

\begin{tabular}{|c|c|c|c|c|}
\hline \multirow{2}{*}{$\begin{array}{l}\text { AUDIT } \\
\text { score }\end{array}$} & \multirow{2}{*}{$\begin{array}{l}\text { Num- } \\
\text { ber }\end{array}$} & \multicolumn{2}{|c|}{ Number (\%) } & \multirow{2}{*}{$\begin{array}{l}\text { Remark } \\
\text { (Number) }\end{array}$} \\
\hline & & Normal & $\begin{array}{r}\text { Abnor- } \\
\text { mal }\end{array}$ & \\
\hline Level 0 & 10 & $\begin{array}{c}10 \\
(100.00)\end{array}$ & 0 & \\
\hline Level 1 & 15 & $10(66.67)$ & $5(33.33)$ & $\begin{array}{l}\text { Abnormal } \\
\text { diastolic } \\
\text { function (5) }\end{array}$ \\
\hline Level 2 & 15 & $8(53.33)$ & $7(46.67)$ & $\begin{array}{l}\text { Abnormal } \\
\text { diastolic } \\
\text { function (3) } \\
\text { Pseudonormal } \\
\text { diastolic } \\
\text { function (4) }\end{array}$ \\
\hline Level 3 & 15 & $8(53.33)$ & $7(46.67)$ & $\begin{array}{l}\text { Abnormal } \\
\text { diastolic } \\
\text { function (3) } \\
\text { Pseudonormal } \\
\text { diastolic } \\
\text { function (4) }\end{array}$ \\
\hline Level 4 & 15 & $8(53.33)$ & $7(46.67)$ & $\begin{array}{l}\text { Abnormal } \\
\text { diastolic } \\
\text { function (5) } \\
\text { Pseudonormal } \\
\text { diastolic } \\
\text { function (2) }\end{array}$ \\
\hline
\end{tabular}

\subsection{Systolic Function in Asymptomatic Alcoholics}

In this study, we found that asymptomatic alcoholics had a significantly decreased left ventricular ejection fraction at an AUDIT score level of 4 when compared with control. Diffuse hypokinesia of the left ventricle and severe reduction in ejection fraction $(30 \%)$ has been detected in chronic excessive consumption of alcohol ${ }^{14}$. The alcoholics had a significantly lower mean ejection fraction than control subjects ${ }^{\underline{14}}$.Echocardiography in patients with alcohol consumption of more than 13 grams per day over more than 5 years detected LV dilatation, wall thinning, hypertrophy and decreasing systolic and diastolic function ${ }^{15}$. The report also concluded that the deterioration of systolic function is significantly related to the level of alcohol consumption and duration of abuse ${ }^{15}$. Several studies have supported that ethanol and acetaldehyde (ethanol metabolite) have caused cardiac damage. Acetaldehyde, an alcohol metabolite, is a potent oxidant, leading to the formation of oxygen radicals and subsequent endothelial and tissue dysfunction. Acetaldehyde may also result in the impairment of mitochondrial phosphorylation $\frac{16}{}$. The myocyte mitochondria in the hearts of persons exposed to alcohol was found to be abnormal in structure and this may be an important factor in the development of $\mathrm{ACM}^{17}$. The other mechanisms for heart injury include a direct inhibition of calcium-myofilament interaction, lipopigment accumulation within the myocyte and inhibition of protein synthesis, reduction of receptor expression, abnormal membrane structure and myocarditis $\frac{18-22}{}$.

\subsection{Diastolic Function in Asymptomatic Alcoholics}

This study showed that the Doppler LV diastolic filling variables of alcoholic beverage drinkers and controls were not different. However, LV diastolic dysfunction was detected in alcoholic beverage drinkers with AUDIT score levels between 1-4. The changes of LV function may be associated with the amount and duration of alcohol consumption. It has been reported that diastolic function impairment was present in one-third of alcoholics without cardiomyopathy and was more frequent when systolic dysfunction coexists ${ }^{\underline{Z}}$.The other research found that abnormal diastolic dysfunction grades 1 and 2 were detected in an alcoholic group after a one year follow up assessment ${ }^{23}$. Therefore, a Doppler echocardiogram can detect abnormal LV diastolic function in alcoholic beverage drinkers with asymptomatic cardiomyopathy who have been drinking for more than 5 years.

\subsection{Limitations}

A small sample was used and cardiomyopathy was asymptomatic in the alcoholic beverage drinkers.

\section{Conclusions}

The systolic LV function was significantly decreased at an AUDIT score of level 4 when measured by M-mode 
echocardiography. Abnormal diastolic dysfunction was detected in AUDIT scores from level 1-4. Therefore, the AUDIT evaluation form may be of benefit in screening for the risk of heart failure in alcoholic beverage drinkers in primary health care and may suggest follow up echocardiogram testing.

\section{Acknowledgement}

Division of Research Administration, Naresuan University, supported this study.

\section{References}

1. Lim SS, Vos T, Flaxman AD, Danaei G, Shibuya K, AdairRohani $\mathrm{H}$, et al. A comparative risk assessment of burden of disease and injury attributable to 67 risk factors and risk factor clusters in 21 regions, 1990-2010: A systematic analysis for the Global Burden of Disease Study 2010, The Lancet. 2012 Dec; 380(9859):2224-60. Crossref.

2. Maisch B. Alcoholic cardiomyopathy. The result of dosage and individual predisposition, Herz. 2016Sep;41(6):484-93. Crossref. PMid: 27582365 PMCid:PMC5013142.

3. Lamari A, Dattilo G, Zito C, Morabito G, Tulino D, Altieri $\mathrm{T}$, et al. A dilated alcoholic cardiomyopathy, International Journal of Cardiology. 2011 Jun; 149(3):95-6. Crossref. PMid:19324436.

4. Mariann RP. Alcoholic cardiomyopathy incidence, clinical characteristics, and pathophysiology, Chest. 2002 May; 121(5):1638-50.

5. Lazarevic AM, Nakatani S, Neskovic AN, Marinkovic J, Yasumura Y, Stojicic D, et al. Early changes in left ventricular function in chronic asymptomatic alcoholics: Relation to the duration of heavy drinking, Journal of the American College of Cardiology. 2000 May; 35(6):1599-606. Crossref.

6. Kupari M, Koskinen P, Suokas A, Ventila M. Left ventricular filling impairment in asymptomatic chronic alcoholics, The American Journal of Cardiology. 1990 Dec; 66(20):1473-7. Crossref.

7. Fernández-Solà J, Nicolás JM, Paré JC, et al. Diastolic function impairment in alcoholics, Alcoholism: Clinical and Experimental Research. 2000 Dec; 24(12):1830-5. Crossref. PMid: 11141042.

8. Erbel R, Schweizer P, Krebs W, Meyer J, Effert S. Sensitivity and specificity of two-dimensional Echocardiography in detection of impaired left ventricular function, European Heart Journal. 1984 Jun; 5(6):477-89. Crossref. PMid: 6745290 .
9. Fleming MF, Manwell LB, Barry KL, Johnson K. At-risk drinking in an HMO primary care sample: prevalence and health policy implications, American Journal of Public Health. 1998 Jan; 88(1):90-3. Crossref. PMid: 9584040 PMCid:PMC1508398.

10. Silpakit $\mathrm{P}$, Kittirattanapaiboon $\mathrm{P}$. The alcohol use disorders identification test: Guidelines for use in primary care. 1st Ed. Bangkok: Tantawanpaper Company; 2009. p. 1-41. PMid:19947797.

11. Thamarangsi T. Thailand: Alcohol today, Addiction. 2006 Jun; 101(6):783-7. Crossref. PMid: 16696622.

12. Ucharattana P, Khaikeow S, Punsakd W, Hoontrakul S. Alcohol consumption behavior of urban Thai: The Banbu community, Bangkok-Noi district, Bangkok, Journal of Nursing Science. 2011 Jan; 29(1):53-62.

13. Suwanakitch P, Weeraphan C, Honman S, Sriprajan A, Thongsri T. Electrocardiogram characteristics in alcoholic beverage drinker males, Srinagarind Medical Journal. 2016 Jul; 31(4):180-5.

14. Urbano-Marquez A, Estrich R, Navarro-Lopez F, Grau JM, Mont L, Rubin E. The effects of alcoholism on skeletal and cardiac muscle, The New England Journal Medicine. 1989 Feb; 320(7):409-15. Crossref. PMid: 2913506.

15. Rajzer M, Mertyna P, Betkowska-Korpala B, KaweckaJaszcz K. The effect of chronic alcohol consumption on systolic and diastolic left ventricular function, Przeglad Lekarski. 2004; 61(9):895-901. PMid: 15803894.

16. Piano MR, and Phillips SA. Alcoholic cardiomyopathy: Pathophysiology insights, Cardiovascular Toxicology. 2014 Dec; 14(4):291-308. Crossref. PMid: 24671642 PMCid: PMC4177522.

17. Fatjó $F$, Fernández-Solà J, Lluís $M$, Elena $M$, Badía E, Sacanella E, Estruch R, Nicolás J-M. Myocardial Antioxidant Status in Chronic Alcoholism, Alcoholism: Clinical and Experimental Research. 2005; 29(5):864-70. Crossref. PMid: 15897732.

18. Figueredo VM, Chang KC, Baker AJ, Camacho SA. Chronic alcohol-induced changes in cardiac contractility are not due to changes in the cytosolic $\mathrm{Ca}^{2+}$ transient, American Journal Physiology. 1998 Jul; 275:122-30. Crossref.

19. Tiernan JM, Ward LC. Acute effects of ethanol on protein synthesis in the rat, Alcohol and Alcoholism. 1986 Jan; 21:171-79. PMid: 3741552.

20. Preedy VR, Patel VB, Why HJ, Corbett JM, Dunn MJ, Richardon PJ. Alcohol and the heart: Biochemical alterations, Cardiovascular Research. 1996; 31(1):139-47. Crossref.

21. Meehan J, Piano MR, Solaro RJ, Kennedy JM. Heavy long-term ethanol consumption induces an alpha- to beta-myosin heavy chain ISO form transition in rat, Basic Research Cardiology. 1999; 94(6):481-8. Crossref. PMid: 10651160. 
22. Capasso JM, Li P, Guideri G, Malhotra A, Cortese R, Anversa P. Myocardial mechanical, biochemical, and structural alterations induced by chronic ethanol ingestion in rats, Circulation Research. 1992 Aug; 71(2):346-56. Crossref. PMid: 1385762.
23. Somani PO, Contractor Q, Chaurasia AS, Rathi PM. Diastolic dysfunction characterizes cirrhotic cardiomyopathy, Indian Heart Journal. 2014 Nov; 66(6):649-55. Crossref. PMid: 25634400 PMCid: PMC4310959. 